\title{
Correction to: Extreme waves induced by cyclone Nargis at Myanmar coast: numerical modeling versus satellite observations
}

\section{Thit Oo Kyaw ${ }^{1}$ (D) Miguel Esteban ${ }^{1} \cdot$ Martin Mäll ${ }^{1} \cdot$ Tomoya Shibayama $^{1}$}

Published online: 23 March 2021

(c) Springer Nature B.V. 2021

\section{Correction to: Natural Hazards https://doi.org/10.1007/s11069-021-04511-4}

The article, Extreme waves induced by cyclone Nargis at Myanmar coast: numerical modeling versus satellite observations, written by Kyaw, T.O., Esteban, M., Mäll, M. et al., was originally published online on the publisher's internet portal on 15 February 2021 with Open Access under a Creative Commons Attribution 4.0 International License. With the author's decision to cancel Open Access the copyright of the article changed on 9 March 2021 to (C) The Author(s), under exclusive licence to Springer Nature B.V. 2021 with all rights reserved.

Publisher's Note Springer Nature remains neutral with regard to jurisdictional claims in published maps and institutional affiliations.

The original article can be found online at https://doi.org/10.1007/s11069-021-04511-4.

Thit Oo Kyaw

thit_oo_kyaw@toki.waseda.jp

1 Department of Civil and Environmental Engineering, Faculty of Science and Engineering, Waseda University, 3-4-1 Okubo, Shinjuku-ku, Tokyo 169-8555, Japan 